\title{
Cervical Disc Herniation and Central Horner Syndrome
}

\section{Hérnia de disco cervical e síndrome de Horner central}

\author{
Luis Rocha ${ }^{1}$ Mário Gomes ${ }^{1}$ Ernesto Carvalho ${ }^{1}$ \\ ${ }^{1}$ Serviço de Neurocirurgia, Centro Hospitalar do Porto, Porto, \\ Portugal \\ Arq Bras Neurocir 2016;35:315-318
}

\begin{abstract}
Address for correspondence Luis Rocha, MD, Serviço de Neurocirurgia, Centro Hospitalar do Porto, Largo Prof. Abel Salazar, 4099-001 Porto, Portugal (e-mail: rocha.Im@gmail.com).
\end{abstract}

\begin{abstract} Keywords

- síndrome de Horner central

- spinal cord lesion

- cervical disc herniation

Central Horner syndrome is a rare condition, comprising a unique pathophysiological phenomenon. It results from vascular lesions, head or thoracic trauma. We describe a case of Horner syndrome associated to cervical disc herniation, and first-order neuron compression. To our knowledge, this is the second case reported to date in the literature.

A síndrome de Horner central é uma condição rara, que compreende um fenómeno fisiopatológico singular. Resulta de lesões vasculares, trauma cerebral ou torácico. Descrevemos um caso de síndrome de Horner associado a hérnia de disco cervical, com lesão de primeiro neurónio. De acordo com a revisão, é o segundo caso reportado na literatura.

\section{Resumo}

Palavras-chave

- síndrome de Horner central

- lesão medular

- hérnia de disco cervical
\end{abstract}

\section{Introduction}

Horner syndrome, or oculosympathetic dysfunction, was described by the Swiss ophthalmologist Friedrich Horner in $1869,{ }^{1}$ and represents the interruption of the cervical sympathetic nervous system. It is characterized by a symptom triad: ptosis (upside down ptosis), pupillary miosis and facial anhidrosis, although some authors associate a fourth symptom to the syndrome, facial hyperemia. ${ }^{2}$ It is an unusual entity that has no relation to age, gender or race. The syndrome prognosis depends on the etiology, and underlying patient condition. This case report refers to a rare cause for this entity, which resulted from the compression of the cervical sympathetic preganglionic nuclei by cervical disc core herniation. ${ }^{3,4}$

\section{Case Report}

A fifty-five years-old patient with complaints of neck and shoulder pain for a week, without reference to a triggering factor, namely exercise or a traumatic event. The symptoms had increased in the 24 hours previous to the hospital observation, without any relief with immobilization or postural correction. Four hours after pain exacerbation, he described motor deficit of right side limbs, without other neurological disorder. received

August 4, 2016

accepted

September 12, 2016

published online

October 17, 2016
DOI http://dx.doi.org/

10.1055/s-0036-1593507. ISSN 0103-5355.
Copyright $\odot 2016$ by Thieme-Revinter

Publicações Ltda, Rio de Janeiro, Brazil

\section{License terms}

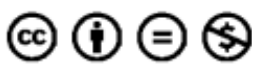




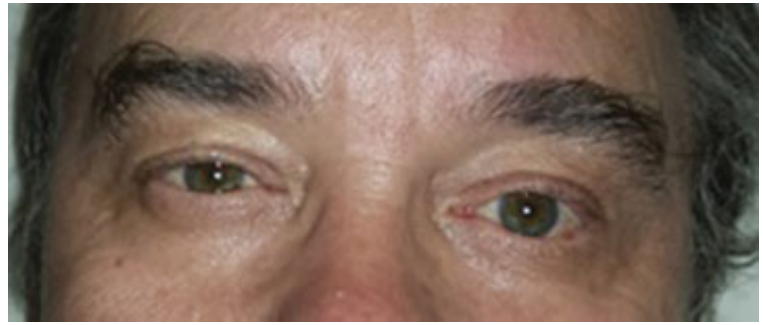

Fig. 1 Preoperative photo. Right upside down ptosis and miosis.

Physical examination showed decreased muscle strength on the right arm and leg, grade 4 on Medical Research Council (MRC) scale, impairment of sensory function below C6-C7 dermatome level, increased deep tendon reflex at upper and lower right limbs, and positive Babinski sign. The cranial nerves exam showed anisocoria, with right pupil miosis and slowed photo-motor response, combined with upper right eyelid ptosis and elevation of the lower eyelid ( - Fig. 1). The patient presented facial anhidrosis, but he refused starchiodine test. The ciliospinal reflex was absent on the right side, and no other abnormal finding was detected through cranial nerves exam. Brain computed tomography (CT) was normal, but cervical CT and cervical magnetic resonance imaging (MRI) showed a stenotic cervical spinal canal with disc protrusions at C3-C4 (major) and C5-C6, with evident spinal cord compression. Magnetic resonance imaging (T2 sequence) revealed spinal cord hyperintensity on the described levels; however, it had been conditioned by motion artifact (-Fig. 2).

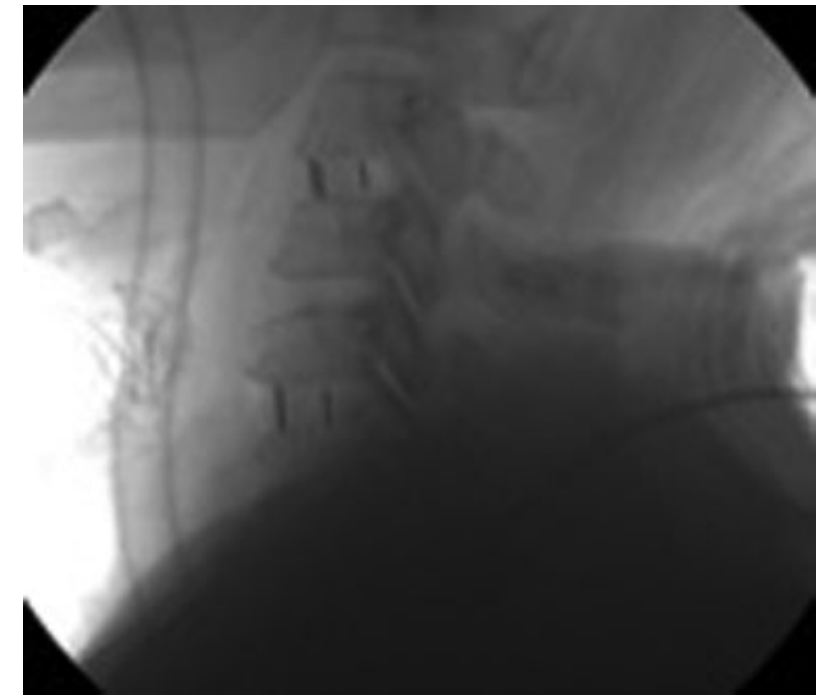

Fig. 3 Postoperative X-ray - C3-4 and C5-6 intersomatic PEEK cages.

Patient was submitted to anterior cervical discectomy and fusion of C3-C4 and C5-C6, with placement of intervertebral polyetheretherketone (PEEK) cages on both levels (-Fig. 3 ). He presented postoperative motor recovery, but sustained right pupil miosis and upside down ptosis (-Fig. 4). On the first month evaluation, patient showed clear recovery, without motor or sensory deficit, and no evidence of oculosympathetic dysfunction (-Fig. 5). Due to the progressive improvement of all the deficits, and the absence of identifiable lesions on brain CT, we decided not to conduct postoperative brain MRI.

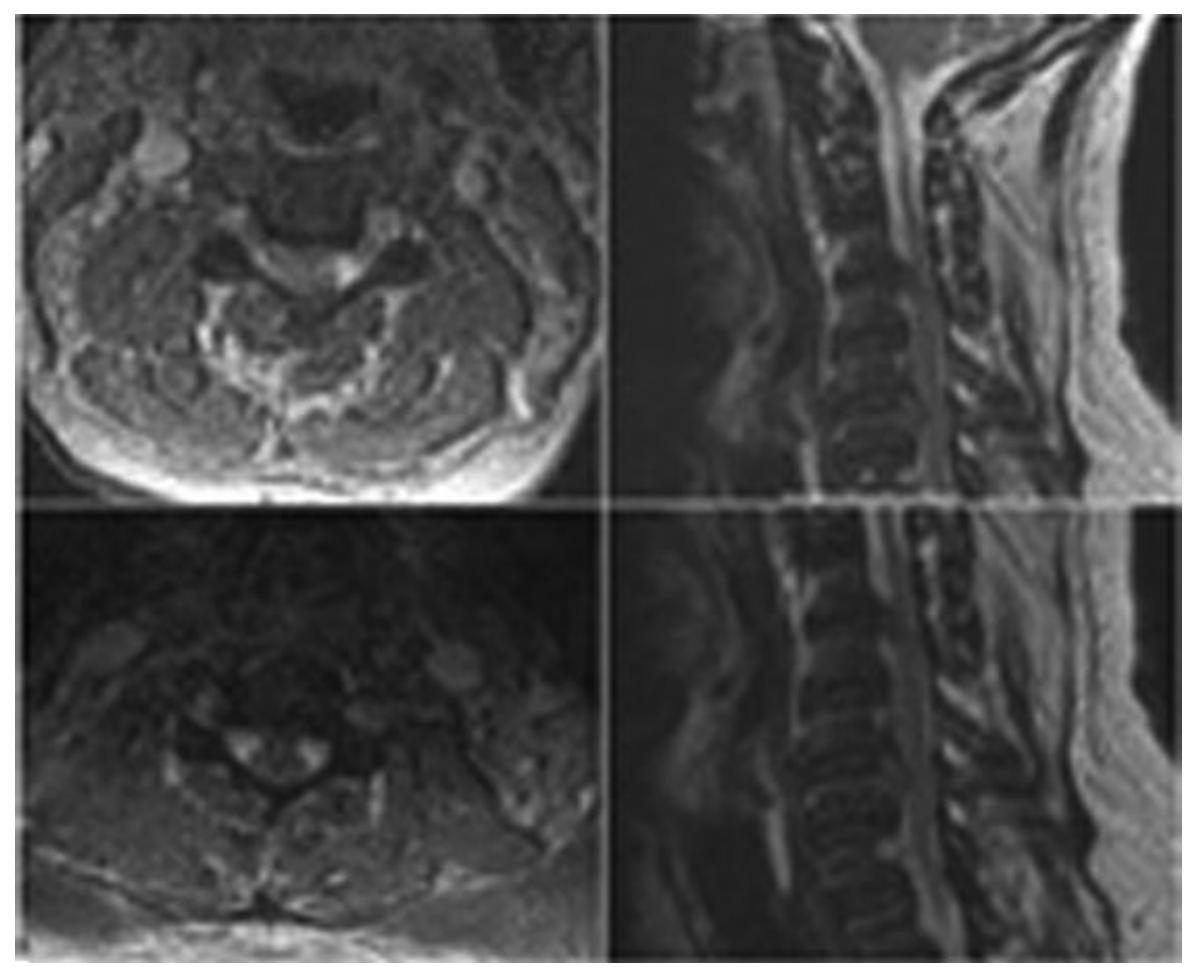

Fig. 2 Preoperative MRI - C3-4 and C5-6 disc herniation with T2/FLAIR hyperintense spinal cord. 


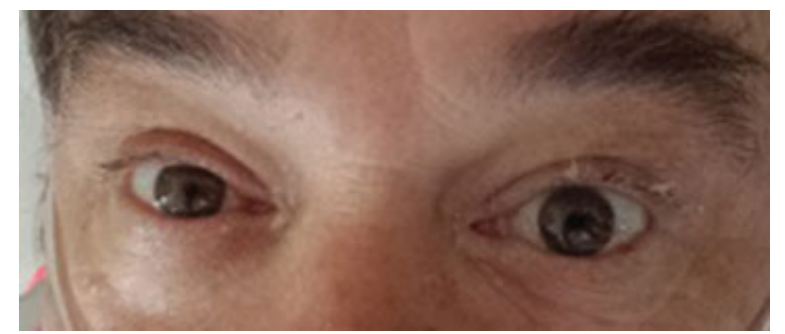

Fig. 4 Immediate postoperative photo. Right upside down ptosis and miosis.

\section{Discussion}

Horner Syndrome etiology is diverse, from congenital, hereditary to acquired causes, which highlights the trauma. ${ }^{5,6}$ It may arise from brachial plexus lesions, chest, cervical or thoracic spine injury, tumor lesions, such as Pancoast, or carotid dissecting aneurysms. It is an entity repeatedly associated with thoracic, throat and neurological surgical procedures. A concern on anterior cervical discectomy, related to longus colli sympathetic chain retraction injury. $^{7,8}$

The sympathetic chain is a three-neuron pathway that originates in the hypothalamus. The first-order neuron runs from the posterolateral hypothalamus to the midbrain and pons. It extends to spinal cord intermediate-lateral column, between C8 and T2 (ciliospinal center of Budge). The secondorder neuron consists on preganglionic pupil-motor fibers, emerging from $\mathrm{T} 1$ and extends to the cervical sympathetic chain, in close relation to the pulmonary apex and subclavian artery. The trunk enters the superior cervical ganglion where it synapses with postganglionic neurons at the carotid bifurcation level (C3-C4). It surrounds the internal carotid artery to the distal structures, covering the cavernous sinus, and follows the VI cranial pair (abducens) and ophthalmic branch of $\mathrm{V}$ cranial pair (trigeminal), innervating the pupillary dilator system, Muller muscle and the vascular complex of the face. ${ }^{8-10}$ The rostral ventrolateral medulla contains premotor neurons controlling cardiovascular conditions, whereas rostral medullary raphe regions are a candidate source of sympathetic premotor neurons for thermoregulatory functions

The network interruption can be central, from the hypothalamus to C8-T2 level, or peripheral, including the cervical sympathetic chain, superior cervical ganglion or the internal carotid artery, with the classification of pre or postganglionic. 8,10

The occurrence of central Horner syndrome is relatively uncommon, and can usually be identified by the concomitant presence of hypothalamic, brainstem, or spinal cord signs and symptoms, which help to localize the lesion. ${ }^{11,12}$

This entity is not associated to the so common cervical spondylotic myelopathy. Myelopathy occurs as result of three important pathophysiological factors. Static mechanical factors, dynamic-mechanical factors, and spinal cord ischemia. ${ }^{11,13}$ It damages the posterior columns, spinocerebellar, and corticospinal tracts. Although as the cortico-

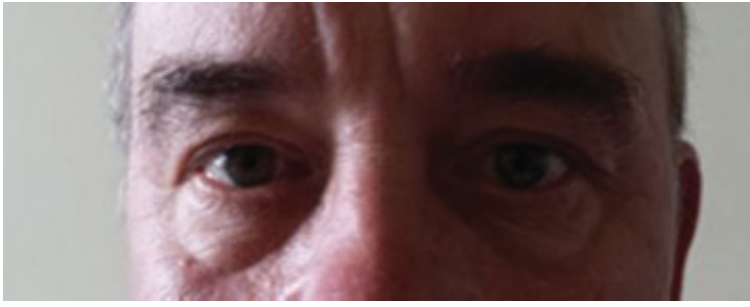

Fig. 5 First month follow-up photo. Oculosympathetic recovery.

spinal tract is first affected during spinal cord compression because it has a watershed arterial supply, the first-order neurons of sympathetic chain localized on Budge center, immediately lateral to the dorsal gray, are preserved by a common anterior and posterior blood supply. The descending sympathetic tract presents a lateral location that preserves it from mechanical trauma or compression.

The most typical presentation occurs as part of the lateral medullary syndrome (Wallenberg syndrome) due to posteriorinferior cerebellar artery or distal vertebral artery stroke. ${ }^{14-16}$ It manifests with the common symptom triad, but anhidrosis usually affects ipsilateral hemibody (not only the face). 3,10 Patients with preganglionic lesions may have flush. This symptom, also called harlequin effect, occurs with exercise in some patients. ${ }^{5}$ Patients with postganglionic lesions may report ipsilateral orbital pain or migraine-like headache.

Differential diagnosis is required in all situations, especially on such unusual clinical setting, which combines a pyramidal pathway lesion together with the sympathetic nervous system impairment. It is necessary to consider the hypotheses of ischemic vascular injury, subarachnoid hemorrhage, epidural hematoma and space occupying lesions. ${ }^{4,6,10,12,13,15,16}$ As a complementary diagnostic method, MRI assumed main importance to differential diagnosis in Horner Syndrome, like in the case of carotid artery dissection, spinal cord infarction, and cervical or thoracic injury. $^{10,13,16}$

As shown, the present case constitutes a first-order neuron lesion. It resulted from the spinal cord compression by a right lateralized disc herniation and narrowing of the spinal canal, which affected the intermediate-lateral column. Radiographic evaluation excluded major brain lesions but showed spinal cord hyperintensity on T2/ Fluid-Attenuated Inversion Recovery (FLAIR), mainly at C3-C4 level, an unusual location to cause Horner syndrome. Even in a trauma situation this would generally be ascribed to lesions at C5-C6 and $\mathrm{T} 1-\mathrm{T} 2 .^{14}$

Neurosurgical intervention was crucial in this case. ${ }^{4,6}$ Recovery did not happen immediately after surgery, although motor function, pupillary and eyelid symmetry were restored in the following days.

In our research on PubMed and Google Scholar, we found that only the work of Hyunjin Ma and Insoo Kim, ${ }^{3}$ reports Horner Syndrome due to a large left paramedian disc herniation with cord compression at the C4-5 level. Similarly to our case, it also presented total recovery after decompression with cervical discectomy and arthrodesis. 


\section{Conclusion}

Horner syndrome is a rare clinical entity, even more unusual when related to cervical disc herniation. This is a case report with fast clinical progression, without previous symptoms, obvious trauma or cervical spine instability signs. In such cases, clinical and image findings are paramount, and timely surgery might dictate the patient's prognosis.

\section{Conflict of Interest}

None of the authors has any potential conflict of interest.

\section{References}

1 Horner F. Über eine Form von Ptosis. Klin Monatsbl Augenheilkd. 1869;7:193-198

2 van der Wiel HL. Johann Friedrich Horner (1831-1886). J Neurol 2002;249(5):636-637

3 Ma H, Kim I. Horner Syndrome associated with a Herniated Cervical Disc: A Case Report. Korean J Spine 2012;9(2): 108-110

4 Rumana CS, Baskin DS. Brown-Sequard syndrome produced by cervical disc herniation: case report and literature review. Surg Neurol 1996;45(4):359-361

5 Roth EJ, Park T, Pang T, Yarkony GM, Lee MY. Traumatic cervical BrownSequard and Brown-Sequard-plus syndromes: the spectrum of presentations and outcomes. Paraplegia 1991;29(9):582-589
6 Edwards A, Andrews R. A case of Brown-Sequard syndrome with associated Horner's syndrome after blunt injury to the cervical spine. Emerg Med J 2001;18(6):512-513

7 Allen AY, Meyer DR. Neck procedures resulting in Horner syndrome. Ophthal Plast Reconstr Surg 2009;25(1):16-18

8 Civelek E, Karasu A, Cansever T, et al. Surgical anatomy of the cervical sympathetic trunk during anterolateral approach to cervical spine. Eur Spine J 2008;17(8):991-995

9 Mariniello G, Annecchiarico H, Sardo L, Buonamassa S, de Divitiis E. Connections of sympathetic fibres inside the cavernous sinus: a microanatomical study. Clin Neurol Neurosurg 2000;102(1):1-5

10 Reede DL, Garcon E, Smoker WR, Kardon R. Horner's syndrome: clinical and radiographic evaluation. Neuroimaging Clin $\mathrm{N}$ Am 2008;18(2):369-385, xi

11 Lee JH, Lee HK, Lee DH, Choi CG, Kim SJ, Suh DC. Neuroimaging strategies for three types of Horner syndrome with emphasis on anatomic location. AJR Am J Roentgenol 2007;188(1): W74-81

12 Almog Y, Gepstein R, Kesler A. Diagnostic value of imaging in horner syndrome in adults. J Neuroophthalmol 2010;30(1):7-11

13 Panciani PP, Forgnone S, Fontanella M, Ducati A, Lanotte M. Unusual presentation of a spontaneous spinal epidural haematoma. Acta Neurol Belg 2009;109(2):146-148

14 Digre KB, Smoker WR, Johnston P, et al. Selective MR imaging approach for evaluation of patients with Horner's syndrome. AJNR Am J Neuroradiol 1992;13(1):223-227

15 Shen CC, Wang YC, Yang DY, Wang FH, Shen BB. Brown-Séquard syndrome associated with Horner's syndrome in cervical epidural hematoma. Spine 1995;20(2):244-247

16 Sacco RL, Freddo L, Bello JA, Odel JG, Onesti ST, Mohr JP. Wallenberg's lateral medullary syndrome. Clinical-magnetic resonance imaging correlations. Arch Neurol 1993;50(6):609-614 